\title{
8. Conclusions
}

The objective of this study has been to enhance our understanding of the individual- and country-level determinants of retirement timing in contemporary Western Europe, with a focus on social stratification. I have gathered empirical evidence about retirement preferences and behaviour using four different largescale survey data sets and miscellaneous methods of statistical analysis. Special attention has been paid to the patterns of labour-force withdrawal in Germany and Spain.

In the second chapter, I put forward the view that none of the existing theoretical approaches to retirement and early exit from work are by themselves sufficient to explain why certain workers retire later than others. Building on the life course paradigm and social class theory, I have outlined a novel analytical framework for the study of differential retirement behaviour (chapter 3). It is based on the distinction of two kinds of social mechanisms: those which alter the opportunity set available to older workers (constraints) and those which affect these workers' decisions within a given range of feasible actions (choice). Pecuniary incentives inherent in pension systems as well as firm-sponsored plans influence retirement ages because they dictate the terms of trade in workers' instrumental work-leisure decisions. Crucially, however, incentives can only alter the timing of work withdrawal of individuals who dispose of the alternative option to remain employed in the labour market. By contrast, the retirement timing of older workers whose employability is severely limited due to disabilities or job loss is determined by precisely these employment constraints, which push them into early retirement. On theoretical grounds, I have identified gender and social class as the most pertinent axes of stratification with respect to group differences in retirement opportunities. Neither dimension had received due attention in studies on retirement behaviour until this point. Hence, the analyses comprised in this study have been tailored to the task of examining the influence of class and gender on retirement timing.

Despite having been addressed in a number of qualitative studies, the previous retirement literature lacks a systematic account that pays heed to the role of soft factors (such as age norms or work orientations) in exit from work. Rather, push and pull approaches to retirement timing make opposed, but equally simplifying assumptions regarding retirement preferences. The available survey evidence about age norms of retirement is limited as well. Correspondingly, there are few representative studies of retirement behaviour which would take age norms or work orientations adequately into consideration. Certainly for Western Europe, there is dearth of knowledge concerning group differences in terms of norms of aging in the population. To fill this void, in the fourth chapter, I have set out and tested a series of theoretical arguments about social heterogeneity in terms of age norms directed specifically at withdrawal

\section{(cc) BY-NC-ND}


from work. The insights gained have then been used to analyse social variability in actual retirement behavior in the subsequent case studies of Spanish and German retirement.

Table 8.1 gives an overview of the key empirical findings of this study, the implications of which are discussed in the remainder of this concluding chapter. The main contributions fall under the following headings: 1) the study places age-graded social norms on the agenda of quantitative retirement research; 2) it has shown manifold ways in which gender differences are relevant for social variability in retirement ages; 3 ) it has pinpointed the genuine impact of social class on retirement behavior; and finally, 4) the study contributes to the comparative retirement literature by focusing on how micro-macro interactions influence country and regime differences.

\section{Retirement Age Norms}

Chapter four of this study has been dedicated to the scrutiny of retirement age norms using micro data from the European Social Survey (ESS). The first notable finding consists in the pervasiveness of these norms. The pluralisation of career trajectories during the last decades notwithstanding, the vast majority of Western Europeans aged over 50 endorse specific social norms regarding the adequate timing of retirement. While many approve of early exit from work there is also a substantial minority that sustains norms of late exit. After all, age norms impose rather clear-cut boundaries on the timing of retirement: $80 \%$ of respondents think that men or women are too old to work when they are over 70 years old. And $85 \%$ agree that a man or woman is too young to retire before age 40 .

Furthermore, my analyses have revealed considerable group-specific differences with regard to the age norms of retirement, which, by this token, are adequately understood as "local norms" (Bicchieri 2006), as they prescribe varying retirement ages for different target groups. Specifically, I have established strong class differentials in terms of norms of aging. Huge differences have been found between the working class on the one side and the service class and petite bourgeoisie on the other. The latter classes hold age norms that are much more supportive of late exit than the former. Employees in a mixed employment relationship (mostly administrative clerks and lower technicians) have similar attitudes towards male age norms to the working class but occupy an in-between position when it comes to women's retirement. In this way, the type of employment relationship is identified as the crucial determining factor of retirement age norms in Western Europe. Overall, the analysis is a case in point for the continued potential of class analysis in research on work-related attitudes. 
Overview of Key Findings.

\begin{tabular}{|c|c|c|}
\hline & Issue & Finding \\
\hline 1 & $\begin{array}{l}\text { Pervasiveness of age } \\
\text { norms of retirement in } \\
\text { contemporary Western } \\
\text { Europe }\end{array}$ & $\begin{array}{l}\text { Age norms are very widely endorsed among older workers. } \\
\text { About } 85 \% \text { of respondents come up with an exact age at } \\
\text { which someone is considered too young to retire or too old } \\
\text { to work. }\end{array}$ \\
\hline 2 & $\begin{array}{l}\text { Gender differences in terms } \\
\text { of social norms regarding } \\
\text { the timing of retirement }\end{array}$ & $\begin{array}{l}\text { Men and women largely agree that women should } \\
\text { retire earlier than men. Ceteris paribus, women support a } \\
\text { somewhat later retirement, especially for women. }\end{array}$ \\
\hline 3 & $\begin{array}{l}\text { Role of social class in the } \\
\text { differential endorsement of } \\
\text { age norms }\end{array}$ & $\begin{array}{l}\text { Other than gender, social class is the most salient } \\
\text { individual-level predictor of retirement age norms. }\end{array}$ \\
\hline 4 & $\begin{array}{l}\text { Impact of social-class } \\
\text { membership on the actual } \\
\text { timing of retirement }\end{array}$ & $\begin{array}{l}\text { Skilled manual workers retire earliest. Routine workers and } \\
\text { low-skilled service workers do not work much longer. The } \\
\text { salariat and petty bourgeoisie remain employed longest. }\end{array}$ \\
\hline 5 & $\begin{array}{l}\text { Gender differences in } \\
\text { retirement timing }\end{array}$ & $\begin{array}{l}\text { Women usually retire earlier than men, but the gender age } \\
\text { gap in retirement is smaller than conventionally suggested. } \\
\text { Moreover, gender disparities in retirement timing differ } \\
\text { between countries. }\end{array}$ \\
\hline 6 & $\begin{array}{l}\text { Relationship between } \\
\text { women's age of retirement } \\
\text { and female labour market } \\
\text { participation }\end{array}$ & $\begin{array}{l}\text { Paradoxically, women in countries with a low female activity } \\
\text { rate retire relatively late. Selection effects induce a negative } \\
\text { relationship between female employment rates and } \\
\text { women's age of retirement. }\end{array}$ \\
\hline 7 & $\begin{array}{l}\text { Social stratification in the } \\
\text { transition to retirement in } \\
\text { Germany and Spain }\end{array}$ & $\begin{array}{l}\text { While social differences in work-exit transitions in Spain are } \\
\text { primarily dictated by push factors, in Germany, pull factors } \\
\text { gain special salience by fostering a comparatively early } \\
\text { retirement of the service class. }\end{array}$ \\
\hline 8 & $\begin{array}{l}\text { Synchronous retirement of } \\
\text { spouses }\end{array}$ & $\begin{array}{l}\text { Having a retired spouse lowers older workers' normative } \\
\text { work attachment. If work withdrawal is not involuntary, } \\
\text { this preference for joint retirement is reflected in actual } \\
\text { behaviour. }\end{array}$ \\
\hline 9 & $\begin{array}{l}\text { Other household effects in } \\
\text { retirement behaviour }\end{array}$ & $\begin{array}{l}\text { In Germany, divorced women postpone retirement, whereas } \\
\text { widowhood leads to early exit from work. In other countries, } \\
\text { no clear effect of partner loss could be found on retirement } \\
\text { timing. }\end{array}$ \\
\hline
\end{tabular}

Source: own elaboration.

Striking findings were brought to light with regard to the gender puzzle in retirement-related social norms. It turned out to be crucial to distinguish between the holders and the target actors of an age norm. An earlier retirement age is generally considered better suited for women than for men. Both sexes largely embrace norms supportive of a traditional gender divide in retirement timing, which dictate that women should retire earlier than men. However, women place the age deadline of retirement for women (i.e. the age when women become too old to work) on average one year later than men do. But under otherwise comparable conditions, women also place the corresponding male age deadline higher than men themselves do. In consequence, the perceived gender gap in 
retirement age norms is about the same in the eyes of women and men, about 4.5 years. One conclusion from this is that women have internalised gendered age norms as much as men have. But everything else being equal, they generally exhibit a greater approval of late-exit norms than men. This finding calls into question the simple hypothesis of the low female work attachment claimed by preference theory (Hakim 1996, 2007).

\section{Retirement and Gender}

In chapter five, I have used data from the Survey of Health, Ageing and Retirement in Europe (SHARE) to, inter alia, analyse the gender divide in retirement timing. The results, based on the pooled sample from eleven Western European countries, show that the traditional gender pattern prevails, as women leave the labour market slightly earlier than men. The gender gap in Western Europe as a whole is small but significant. However, there is considerable country heterogeneity lying beneath the dominant pattern of female early exit. While the sex-based difference in retirement ages is large in some countries, it is small or even "reversed" in others.

How can the ambiguity of these findings be explained? On the one hand, women may retire earlier than men because their disadvantaged job position makes them more vulnerable to being laid off. Moreover, many pension systems traditionally established a lower pension age for women than for men. Arguably, gendered norms of aging reinforce this propensity towards early exit among women, which, in fact, is the dominant pattern in Western Europe. On the other hand, there are also factors that make women exit the labour market later than men. Specifically, women with a low number of pensionable years have stronger economic incentives to remain employed. Moreover, many women often miss eligibility for special early retirement programmes or occupational pensions requiring a minimum number of years of contribution due due their higher likelihood of taking time off of work for domestic reasons, such as birthing children or acting as a caretaker to relatives (Ginn \& Arber 1993, 1996; Schils 2008).

Countries with a low female activity rate in particular tend to be characterised by a small gender difference in retirement ages. This pattern points to a selection process. Accordingly, labour markets with a low share of female workers are likely to produce self-selection in terms of women with high levels of work attachment remaining economically active beyond age 50. This explanation has not been sufficiently acknowledged in the previous literature, which generally treats women as a high-risk group of early exit (but cf. Dahl et al. 2003).

Based on national labour-force surveys, this nexus has been underpinned in the head-to-head comparison between Germany and Spain carried out in the sixth and seventh chapters. Whereas in Germany, only a small proportion 
of women retire after age 60 (the age threshold for the now-obsolete old-age pension for women), in Spain, the retirement age difference between men and women is almost negligible. I maintained that this pattern is chiefly attributable to the confluence of institutional filters and selection effects. While the German welfare state has until recently fostered the traditional gender division of labour through a special old-age pension for women, pension regulations in Spain are formally gender-blind. Consequently, women's retirement behaviour in Spain resembles the behaviour among their male peers to a much larger extent than in Germany.

When comparing the two countries, selection effects gain special salience: the gender gap in retirement is larger in Germany, where many women work past age 50, albeit often part-time. By contrast, in Spain, the gender gap is small, because the labour market essentially only offers women the choice between "exit or full-time" work (Anxo et al. 2007). Correspondingly, Spanish women frequently become inactive during their mid-career phase, particularly if they are low-skilled, married women; in turn, high-skilled women, who often stay single and divorce more frequently, display similar labour market behaviour to men (Garrido 1992).

In conclusion, it is crucial to acknowledge that selectivity is an essential feature of late career exit and that it is inherent in the very definition of retirement. Within a concept of retirement as withdrawal from lifetime employment, selective midlife labour market participation leads to selective patterns of late career exit. To the best of my knowledge, this study is the first in retirement research to concretely and systematically address the question of sample selection in workexit transitions by means of duration selection models.

\section{Retirement and Social Class}

The focal point of this study has been the impact of social-class membership on retirement timing. Chapter five has formulated and tested a set of hypotheses regarding the class-retirement relation in Western Europe. In the two subsequent chapters, these hypotheses were tested in Spain and Germany, bearing in mind the specific contexts and conditions as they apply to older workers in the two selected countries. By reference to the European Socio-economic Classification (ESeC), which has been used throughout for the operationalisation of the class concept, table 8.2 synthesises the respective empirical findings.

Most importantly, the overview demonstrates that social class is a crucial determining factor of retirement timing. The dominant pattern is that the working class leaves work earlier than the service class. Despite disposing of the necessary financial latitude, the salariat does not predominantly choose to retire early. It was shown that this is partly due to better employment opportunities, 
Table 8.2

Social Class and Retirement Timing in Western Europe.

\begin{tabular}{|c|c|c|c|c|c|c|}
\hline \multirow[b]{2}{*}{ Social Class (ESeC) } & \multicolumn{2}{|c|}{ WESTERn EUROPE } & \multicolumn{2}{|c|}{ SPAIN } & \multicolumn{2}{|c|}{ Germany } \\
\hline & Men & Women & Men & Women & Men & Women \\
\hline Higher Salariat & Late & Late & Very Late & Very Late & Average & Average \\
\hline Lower Salariat & (Late) & (Late) & Late & Average & Early & Average \\
\hline Self-employed & \multirow{2}{*}{ Late } & \multirow{2}{*}{ Late } & Late & Late & \multirow{2}{*}{ Very Late } & \multirow{2}{*}{ Very Late } \\
\hline Farmers & & & Late & Average & & \\
\hline Intermediate & \multirow{2}{*}{ (Early) } & \multirow{2}{*}{ (Average) } & \multirow{2}{*}{ Average } & \multirow{2}{*}{ Average } & Early & Early \\
\hline Lower Technicians & & & & & Early & Average \\
\hline $\begin{array}{l}\text { Lower Sales \& } \\
\text { Service }\end{array}$ & (Average) & (Average) & Early & Average & Early & Average \\
\hline Skilled Manual & Early & Early & Average & Very Early & Very Early & $\begin{array}{l}\text { Very } \\
\text { Early }\end{array}$ \\
\hline Routine Workers & Average & Average & Average & Average & Average & Average \\
\hline
\end{tabular}

Source: own elaboration; brackets indicate low degrees of cross-national homogeneity.

which keep down the risk to be laid off or of suffering career-ending disability. It is also plausible that this pattern can be partly attributed to an emphatic work orientation and to the age norms of retirement proscribing a much-anticipated exit from work. Amongst the working class, skilled manual workers tend to stay in the labour market for a shorter time than routine workers or lower sales and service workers. Nevertheless, the divide between blue-collar and white-collar jobs seems to be less prevalent than commonly assumed. Workers with a mixed employment relationship (such as administrative clerks) retire just as early as many working-class individuals.

While for some classes, the generic Western European pattern is representative for most countries - most notably for small employers and the self-employed, who consistently show a propensity for late retirement - there is greater variation across countries regarding the typical work-exit patterns of certain other classes or by gender. Judging from the presented findings, the retirement behaviour of the lower salariat, intermediate workers, and lower sales and service workers are more easily altered by institutional factors than by the retirement behaviour of other classes.

The head-to-head comparison of Germany and Spain illustrates that while class membership is an important predictor of differences in retirement timing in both countries, class differentials are not identical. In Spain, the higher service class and petite bourgeoisie work until much later in life than routine workers. Female skilled manual workers exit the labour market at the earliest age. Hence, 
the class ranking established for Spain by and large corresponds to the generic Western European pattern, with the noteworthy exception of male skilled manual workers, who do not exit the labour market as early as their peers in other countries. In Germany, male and female members of the higher and lower salariat exhibit a rather unusual behaviour: instead of retiring later than routine workers, there is no significant difference to be found. For male employees from the lower salariat, there even seems to be an increased retirement propensity vis-à-vis low-skilled workers. These findings are robust insofar as similar results were found for both countries in chapter 5 using SHARE data.

The deviations from the generic pattern regarding the class-retirement nexus found in Germany and Spain underline the importance of "institutional filters" in deciding which kinds of workers retire early and late respectively. Specifically, the explanation of these differences put forward here emphasises the impact of differential incentives embedded in the pension system. Economic incentives are arguably more consequential for the behaviour of high-skilled workers than for low-skilled workers, who are more vulnerable to employment constraints. In Spain, there are harsh penalties on early exit from work. Service-class employees therefore rarely choose to leave the labour market early. In Germany, on the contrary, the generosity of publicly funded early retirement pathways puts highly skilled workers in the position to exit the labour market relatively early. For instance, the adjustment factor applicable in the case of early oldage pension entrance is far lower than in Spain. Besides, the so-called "old-age part-time work scheme" (Altersteilzeit) fits the specific needs of well-educated workers. Unlike in most countries, the German salariat consequently exhibits similar retirement timing to routine workers. In summary, the institutional design of retirement pathways in Germany has so far promoted an extraordinary pattern of social stratification in labour market withdrawal: the relatively early exit of high-skilled workers.

Social diversity in retirement timing in Spain is essentially structured according to the level of employability of workers. As the table shows, the resultant class-retirement association is similar to most Western European countries. In contrast, in Germany, welfare-state intervention is responsible for a significant modification of the relationship between class position and employment exit, with the service class enjoying privileged access to generous early retirement pathways. I concluded that institutional filters not only affect the average age of work withdrawal but also alter the functioning of class disparities in retirement behaviour.

In comparison with the salience of social class, the importance of education in retirement is limited. As a matter of fact, the level of educational attainment per se does not contribute much to explaining retirement trajectories. This result is consistent across all presented analyses. Education exerts an indirect effect, as credentials and skills act as selection criteria when accessing particular 
occupations and career paths that eventually shape retirement behaviour. Education also unleashes long-term biographic pacing effects through influencing the age at which one enters the job market. But the direct effect of educational titles, once class and career length are controlled for, is of minor relevance.

With respect to class schemes, the upshot is that sociological research would benefit hugely from a greater degree of standardisation and transparency. I have elected the European Socio-economic Classification (ESeC) as class schema for this study, partly because it stands out for the quality of documentation. Moreover, detailed practical research guidance provided by the designing team guarantees a maximum degree of inter-subjective transparency. For class analysis as a research programme, it would be enormously fruitful to improve the replicability of empirical analyses using different class schemes.

\section{Retirement and Cross-Country Diversity}

The previous comparative literature has greatly enhanced our understanding of the way in which the use of early retirement depends on national context (Kohli et al. 1991; Blossfeld et al. 2006; Ebbinghaus 2006a; Schils 2008). In this spirit, the present study has examined cross-country differences in retirement ages in contemporary Western Europe, paying special attention to the alleged regime difference between continental and Southern Europe.

One key conclusion is that the conventional welfare-regime typology does not do a particularly good job of mapping countries according to average retirement age. Specifically, the Southern European countries, usually subsumed under the fragmented regime, do not, as postulated by the regime approach, tend towards lower retirement ages with respect the rest of Western Europe. While Italy indeed exhibits a marked affinity towards early exit, this hypothesis cannot be maintained for the other Southern European countries. Instead, Portugal, Greece, and Spain exhibit at least average retirement ages. This finding, which holds true across different data sources, has been often overlooked because of the common practice of looking at employment rates instead of at retirement ages proper. Nevertheless, what the four countries seem to have in common is a high degree of social variability in retirement timing. In this sense, the notion of a fragmented welfare regime, albeit not defining a homogenous cluster of countries, is not without predictive value for retirement behaviour.

Apart from Italy, the most pronounced early retirement patterns are consistently found in France, Belgium, and Austria. The fact that these latter countries rate quite some years behind Germany and the Netherlands in terms of the prolongation of working life also places into doubt the coherence of the conservative-regime cluster in what concerns retirement timing. Thus, 
the conventional welfare-regime typology is of limited utility for the analysis of early retirement. This conclusion is not entirely new. In fact, Ebbinghaus's (2006a) inquiry into the political economy of early retirement already pointed in this direction by clustering France together with Italy under the label of a "Latin" regime.

In conclusion, rather than proposing a new ad-hoc country classification by adding yet another regime type, I advocate for using such country typologies with great caution. Despite being useful to positing hypotheses, the regime approach should not be applied in a reifying manner. In the end, paying attention to particular countries and their specific institutional canvas is irreplaceable for social research on retirement.

In this vein, I have demonstrated that aggregate country rankings of retirement timing are not properly understood without reference to a series of micro-macro mechanisms. Specifically the empirical evidence presented highlights the role played by institutional filters, selection effects, and compositional effects. Beyond their impact on class and gender patterns in retirement, institutional filters have turned out to be crucial in the family realm. The empirical analyses have shown that the "joint lunches" effect leads to coupled retirement within almost all contexts: married older workers are shown to have a preference for joint retirement. Furthermore, this propensity also makes itself noticeable in retirement behaviour, as long as work withdrawal is not involuntary. On closer scrutiny, even German men turn out to follow this pattern.

By contrast, other family effects strongly hinge on institutional filters. Only in Germany were widowed persons found to exhibit a strong propensity to withdraw from work early. Legal incompatibilities between the receipt of a survivor pension and labour income make widows and widowers tend to leave the labour market prematurely. Conversely, divorced women work until a rather late age in Germany. Despite the pension-sharing legislation in place, it seems that divorce creates the need for women to compensate the forgone years of pension-building by working longer. Overall, the German institutional framework fosters idiosyncratic forms of social stratification in retirement, not only with respect to social class but also with respect to family.

\section{Limitations and Future Research}

While adding novel results to an as yet underdeveloped area of retirement research, the macro-level analyses in chapter four suffer from lack of adequate data. The presented findings suggest that country-specific age cultures are intimately related to the pension legislation in place. Specifically, the national statutory pension age emerges as the institutional feature most closely associated with cross-national variation in retirement age norms. However, the 
question of causality must remain open. Favourable attitudes towards early retirement can just as well be rationalisations of retirement incentives as driving forces of institutional change. Further comparative research using longitudinal data is needed to disentangle institutional, structural, and conventional effects on age-graded social norms. For research on retirement behaviour, likewise, better measures of early retirement incentives are required. In particular, we lack adequate comparable indicators on the retirement-age-specific generosity of the second and third pillar of old-age provision. Ideally, we would have access to information on the instantaneous level of pension entitlements from every pillar of old-age provision at the individual level. In the future, projects with the purpose of matching survey and administrative data are needed to enhance the potential of retirement research.

Another limitation of this study relates to the presumed impact of age norms on retirement behaviour. According to the theoretical framework put forward here, differences in age norms and work orientations eventually co-determine differential retirement timing to the extent that individual actors have the possibility to choose between alternative work-exit trajectories. However, in this study, we have only been able to link these dimensions indirectly, using the findings about retirement attitudes from chapter four to formulate hypotheses regarding retirement behaviour, as well as by applying a competing risks framework. With an adequate data set, it would be a promising research agenda to model the influence of age norms and retirement preferences as an immediate predictor of retirement behaviour.

Moreover, the above-emphasised issue of selection effects in retirement timing needs further investigation. In line with the comparative findings from the fifth chapter, the duration selection models presented in the sixth and seventh chapters showed that there is strong self-selection in even late-career employment. However, the gathered evidence could not substantiate the claim that this selectivity subsequently modifies the patterns of social variability in retirement timing. This inconsistency calls for further testing. Future research could estimate more elabourate duration selection models, using richer data sets. It could also assess whether there is a dialectical relationship between female mid-career labour market participation and retirement behaviour in a cross-sectional time-series framework. Such an analysis would ideally be carried out for a maximum number of developed countries, using methods of longitudinal data analysis.

For practical reasons, one fundamental trade-off in empirical social research is between comparisons across time and space. In the present study, I chose to largely put aside questions of social change in order to be able to thoroughly carry out cross-nationally comparative analyses. Although these issues are dealt with extensively elsewhere (Blossfeld et al. 2006; Blossfeld et al. 2011), this dilemma underlines the immense importance of the further development of 
the data infrastructure for social research. In retirement research, as in many other fields, the sophistication of applied statistical models by far outweighs the quality of the available data material. In particular, there is a genuine need for longitudinal international survey projects. The launches of the Survey of Health, Ageing and Retirement in Europe (SHARE) as well as the European Union Survey on Income and Living Conditions (EU-SILC) are important milestones, but it will still take time until the full benefits of longitudinal data collection can be reaped. Though essentially cross-sectional in nature, the European Union Labour Force Survey (EU-LFS) also has the potential to become an important pillar of the research data infrastructure. However, increased international cooperation is required among data producers in the European community to overcome existing limitations and to enhance the availability of comparable data for crossnational research. ${ }^{134}$

\section{Concluding Remarks}

The relationship between social stratification and retirement is double-edged. The sex and class position of an individual determine his or her opportunities at the end of work life-and hence the age of retirement. At the same time, both characteristics are powerful predictors of internalised social norms concerning retirement timing. In very simplified terms, women and members of the working class tend to retire early, whereas men and members of the service class tend to retire late. The differential endorsement of age norms mimics approximately the same pattern. A key point is thus that the class- and gender-differential molding of retirement age norms and preferences corresponds, by and large, to the structure of employment opportunities during late working life.

There are two diametrically opposed ways of interpreting this stylised fact: one interpretation argues, somewhat sarcastically, that if most older workers eventually end up retiring at about the time they want to retire, there is not much reason for concern from an equality point of view. The second interpretation contends that precisely because it shapes not only career opportunities but also individual norms and preferences, the system of social stratification exhibits an immense impact on retirement behaviour, often internalised so that workers "want" to retire at the time dictated by their genders and/or classes. If norms of early exit are rationalisations of labour market constraints instead of

134 The series of European User Conferences for EU-SILC and EU-LFS, which bring together researchers with representatives of Eurostat and national statistical offices, are a step in the right direction. 
manifestations of free will, the relevance of class and gender disparities is even greater.

While the first line of reasoning sees social variability in retirement timing as ultimately driven by heterogeneous preferences, the second one essentially regards class and gender differentials as a consequence of unequal opportunities among older workers. Both perspectives are compatible with the empirical evidence provided in this study, and it is left to reader to decide which one is more compelling. Either way, there can be no doubt that social class and gender are crucial determining factors of retirement behaviour, and that they ought to be included in every attempt to causally explain differential retirement timing in contemporary Western Europe. 